\title{
DOMESTIC SANITARY ENGINEERING IN THE WEST OF SCOTLAND.
}

\author{
By GILBERT THOMSON, AI.A., Assoc.M.Inst.C.E., \\ Jecturer on Sanitary Engineering, Glasyow and IVest of Scotlcml \\ Teclinical College.
}

(Memier.)

W

HEN, in 1883, The Sanitary Institute last held its Congress in Glasgow, $\mathrm{I}$ had the honour of reading a paper entitled "Notes on House Sanitation in and around Glasgow." This was largely a record of observations made in my then position of Resident Engineer to the Association which is now known as the West of Scotland Sanitary Association, and while it was a very crude production, the facts therein given may be noted as a starting point.

Testing had come into prominence, and the various smell tests were $1 \mathrm{~m}$ the point of being superseded by what has since become so widely known as the smoke test. Water testing was scarcely used, and incleed the ordinary methods of construction were so poor that very trifling tests brought much bad work to light. Even in towns cesspools were occasionally found, and drain traps were mostly of an antiquated form, Mr. Buchan's famous ventilating trap being then almost new. Disconnection, which has since become a watchword, was then in its early stages, and was strongly pressed by the eminent pioneers, and by those who, like myself, were working under their guidance. The pan closet was still in common use, and everything was enclosed in more or less elaborate woolwork. As regards sanitary or insanitary construction, every man was a law unto himself.

The change in this last respect is the chief cause of the improvement which has come about. While other causes have been operative, our present standard of work is chiefly due to the exercise by the sanitary authorities of compulsory powers. Opposed by powerful interests, and watched narrowly by keen critics, their work has been done with tact and skill, both in the detection and cure of existing insanitary conditions, and in the prevention of new ones. 'The latter, carried out by means of building' regulations, is perhaps the most important work at present being done in this department of sanitation. 
But some other influences in addition to official pressure deserve mention. Closely connected with it is the training of officials; and the work of examining and certifying sanitary knowledge, which in England is so efficiently carried out by The Sanitary Institute, is no less thoroughly done here by the Incorporated Sanitary Association of Scotland. 'This body has set a standard not lower than that of The Sanitary Institute, and is backed up by the enlightened action of many authorities, who require that their officials should hold its certificate. The education of the plumber is another important factor, and I may be permitted to refer also to another branch of the work done by the Technical College, where within the last dozen years I have had emrolled in my own classes on sanitary engineering considerably over 1,000 students, belonging to every class of sanitary workers. In addition to the direct effect, these various causes have exercised an indirect influence which is simply incalculable.

Our present position might be briefly described by saying that the standard arrangement of to-day is in its essentials very similar to the most advanced work of twenty-one years ago ; that a first-class system of house drainage (there are a great many others) is now made of iron almost throughout; that the old notion of substantial and comfortable-looking woodwork has given place to the new one of impervious and non-absorbent construction; and that everything must now be done to the satisfaction of the sanitary inspector. In every new louse, be it mansion, cottage, or tenement, and in every old one where suspicious circumstances have occurred, the drainage system is, as a matter of course, tested by smoke by the Sanitary Department.

Having thus reviewed our progress up to date, the question which naturally arises is whether our present methods are the best for securing good results now, and satisfactory progress in the future. My opinion is that they are not.

Our present standards of design, construction, and testing, for the great majority of houses, are simply those of the various building regulations. These regulations may be said generally to date ten or a dozen years back, or at least to represent pretty much the practice of that time. Internal evidence suggests that their framers tried to ensure sound work and hoped they would get it, but, after all, had considerable doubts about it. At that time, probably, the doubts were fully justified. But our traclesmen have risen to the occasion, and we now find no difficulty in getting work far better than could then be generally anticipated. On the other hand, the ordinary run of work can only just pass muster, and this not because of any great economy thereby effected, but because our regulations and metliods of inspection do not give any inducement to do better. 


\section{Domestic Sanitary Enginecring in the West of Scotland.}

I am satisfied that it would be possible to bring all work up to the standard which is now regularly attained in high-class work.

Not only would this be possible, but it would be a measure of economy. Our predecessors, in their well-founded suspicion about the work of their dar, devised the plan of various lines of defence; so that if one failed there was another to help. The house drain was to be protected from the sewer, the waste-pipe was to be protected from the soil-pipe, and so forth, with the result that primitive simplicity was replaced by great complication. Numerous pipes were provided, each carefully "disconnectel " from its neighbours, but making a big agrgregate of dirty piping, accompanied by the accumulation of dirty water in the traps. For the same reason, drains, soil-pipes, and waste-pipes must all be outside the walls, so that if leakage occurs the harm done would be less. On the assumption that tightness cannot be secured, all these precautions, elalyorate and costly though they may be, are perfectly sound. But is it necessary to accept that assumption?

It is said that the surest way to make a man dishonest is to suspect him of being so. Similarly, if in our building regulations we assume that we will not get sound workmanship, we have a good chance of seeing our suspicion justified. Our various lines of defence are practically an intimation that we expect weakness in each.

Suppose, on the other hand, we assume that everything will be tight. It would not then mitter whether a drain passed round a house or through it, whether a soil-pipe was inside or outside the wall, nor whether a bathpipe was disconnected. We should get rid of the grotesque notion that two classes of sewage, having their origin in the same apartment and their termination in the same drain, must travel by different routes. This of itself would fully justify what I have said as to economy.

It is obvious that any such change depends on the possibility of ensuring tightness. If this is unattainable, we must stick to our various lines of defence, with all their drawbacks, sanitary, financial, and asthetic. I therefore go on to say, that tightness, for all practical purposes, can be secured by the simple means of effective testing. Others, as well as myself, insist on attaining it, and I can see no good reason why it should not be attained in all work under official supervision.

It need hardly be said that this assumes a surer means of provingr tightness than the smoke test, which is now quite out of date except for exploratory purposes. Water, in some respects very suitable, has the disadvantage of great weight, which implies difficulty in application, irregularity of pressure, and risk of damage. The application of the water test to the drains, and the smoke test to the vertical pipes, is open 
to the obvious objection that, as the strength of a chain is that of its weakest link, so the efficiency of a test is that of its least efficient part. But in the air test there is a simple and convenient means whereby it cun be proved in a few minutes whether or not a clrainage system is tight, and this test $I$ expect will ultimately be adopted as a standard. Speaking from experience, I would say that it is on the whole rather more efficient than water, and of course very much more convenient. The smoke test may be used to locate the defects proved by other means to exist, although it is worthless as a proof of tightness.

What is required for future progress is the universal application of a really searching test. This will produce a standard of construction all round equal to what is now only attained in special cases. This will justify much greater simplicity.

Would the resulting house not be safer than one encircled by a drain, decorated with a forest of outside pipes, and freely sprinkled with tripsnone of the pipes having been tested by anything more severe than smoke, and some, "because they only carry clean water" (which means the discharges from baths, sinks, and the like) never tested at all?

The severe test might be opposed for fear of extra expense, but such objectors might be disarmed by making the change a permissive one. If anyone wishes to build under the present regulations let him do so. But if he is prepared to submit his sanitary system to a searching test, give him in return practical freedom from restriction as to the positions of his various pipes, and let him, if he chooses, abandon disconnection. This would involve no possible hardship, and I am satisfied that before long the latter alternative would be universally adopted, and the inferior class of work would be killed ont. In the meantime houses are going up in all directions, and are being passed by the authorities, with sanitary arrangements which any other specialist, would be bound to condenur.

It is, I think, fair to ask in conclusion, whether our progress during the last ten years has been so slight that the practice of the earlier date forms a proper standard for to-day? If not, then our building regulations should be revised. We often hear about the judicious use of the scrap heap. In the matter of these regulations a similar use might be made of the melting pot.

Mr. T. R. SuItI (Kettering) remarked that it would be interesting to know how, when the air test was applied, the particular point of defect could be found out. In the smoke test, although the pressure might not be so ligh, they could see where it came from. He was not particularly acquainted with the air test, and he thought the witer test was the better one. 


\section{Domestic Sanitury Enginering in the West of Scotlend.}

MIr. A. G. Waluis (Glasgow) said he understood that Mr. Thomson wanted to do away to a large extent with the separate system of drainage and have one common pipe. He was largely in sympathy with that view himself, and thought it was one which should be adopted. But Mr. Thomson did not tonch upon the main difficulty. When work was thoroughly well done in the first instance, would it continue good? His experience had shown him that although he havd the work done in the best possible manner-and he subjected it in the first instance to the water, smoke, and air tests-yet in a few years' time the action of the hot water by the expansion and contraction would destroy the lead joints. He had never found a lead joint give way under the action of cold water only. Where hot and cold water ran alternately it frequently occurred. He knew in his own practice that it did, and having one pipe for the two classes of sewage certainly did increase the risk, although the work might be of high-class character. He agreed with Mr. Thomson as to what he said about the local by-law's. He did not know of late years what the by-laws in England were, but their by-laws in Scotland were rery hard and fast, and insisted on a separate system throughout the whole building. In many cases it was a perfectly ridiculous thing from all points of riew.

Mr. Giluent Thonson (Glasgow), in reply, said that the methods of air testing were several, but the principle was the same in each case. The pipes were closed up, and by some means, wuch as an air-pump, either a low or a severe internal pressure of ail was produced: this was watched by the gauge, which, as he used it, was an ordinary $U$ tube, or "manometer." The operation was simplicity itself, and in his own practice he was in the habit of insisting that the pressure must be retained. He did apply the test to earthenware pipes, but he did not find them stand it as a rule, and for that reason among otleers be had given up the use of such pipes. The air test did not localise the point of defect, but the oljject of the local authorities or of engineers was to see whether or not the work was satisfactory. If the work was satisfactory, then it should stand the test. If not, then it was for the man who had done the work to find out the defect. The remark was made that with air one got a smaller pressure than with water, and that was assumed to be a disadvantage, but his experience did not show that it was so. An air-pressure equal to four or five feet of water was sufticient for any purpose, and it was often very useful to apply a much lower, but uniform, pressure. Mr. Wallis had called attention to what was unduulstedly a difficult point, but his own experience had been that if the system was thoroughly tight to begin with it would, as a rule, remain practically tight for an indefinite length of time. He felt that it was an absurdity to have a double system of drainage for no other reason than to conduct two classes of water into the same sewer, frequently from the same apartment.

Mr. F. Bucklex (Dublin) and the President, Prof. Robinson, also took part in the discussion. 